Figure 1. Mean RA-WIS by allocation group over 2 years of follow-up. Mean \pm Standard Error are plotted.

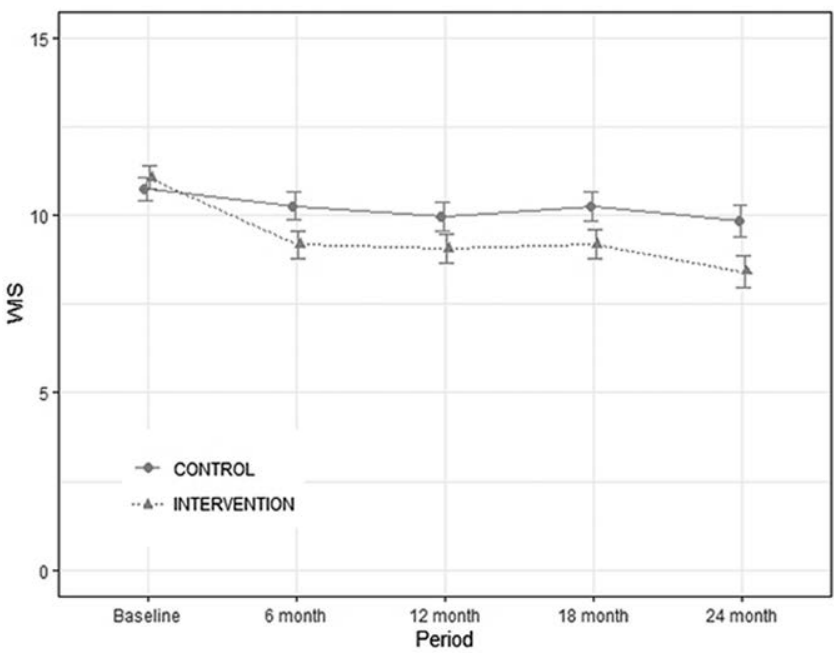

Figure 2. Kaplan Meier analysis of time to work cessation $\geq 2$ months

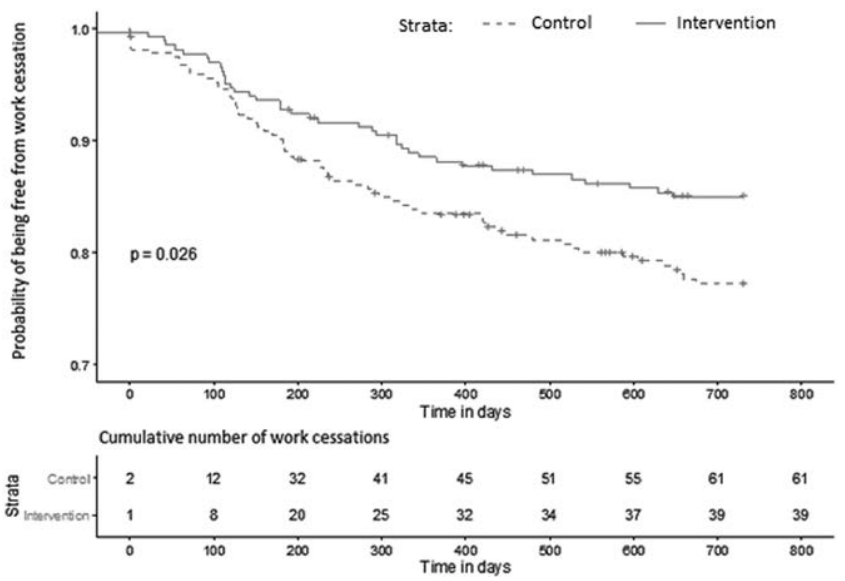

Disclosure of Interests: Andre Luquini: None declared, Yufei Zheng: None declared, Hui Xie: None declared, Catherine Backman: None declared, Pamela Rogers: None declared, Alex Kwok: None declared, Astrid Knight: None declared, Monique Gignac: None declared, Dianne Mosher: None declared, Linda Li: None declared, John Esdaile: None declared, Carter Thorne Consultant of: Abbvie, Centocor, Janssen, Lilly, Medexus/Medac, Pfizer, Speakers bureau: Medexus/ Medac, Diane Lacaille: None declared

DOI: 10.1136/annrheumdis-2020-eular.2383

\section{OP0011 A RANDOMIZED, DOUBLE-BLIND, ACTIVE- CONTROLLED STUDY OF AVACOPAN IN ANTI-NEUTROPHIL CYTOPLASMIC ANTIBODY (ANCA)-ASSOCIATED VASCULITIS}

P. A. Merkel ${ }^{1}$, D. Jayne ${ }^{2}$, H. Yue ${ }^{3}$, T. Schall ${ }^{3}$, C. Kelleher ${ }^{3}$, P. Bekker ${ }^{3}$ on behalf of the ADVOCATE Study Group. ${ }^{1}$ University of Pennsylvania, Rheumatology, Philadelphia, United States of America; ${ }^{2}$ University of Cambridge, Medicine, Cambridge, United Kingdom; ${ }^{3}$ ChemoCentryx, Inc., Mountain View, United States of America

Background: Complement fragment $\mathrm{C} 5 \mathrm{a}$ is strongly linked to the pathogenesis of Anti-Neutrophil Cytoplasmic Antibody (ANCA)-associated vasculitis (AAV). $\mathrm{C} 5 \mathrm{a}$ receptor $(\mathrm{C} 5 \mathrm{aR})$, present on neutrophils, is a G protein-coupled receptor for C5a. Avacopan (previously CCX168) is an orally-administered selective antagonist of C5aR which blocks C5a-induced cell activation. Two previous Phase 2 clinical trials provided evidence of effectiveness of avacopan in AAV and its potential to eliminate extensive use of glucocorticoids (GC) and GC-related toxicities.

Objectives: This Phase 3 study evaluated the efficacy and safety of avacopan for the treatment of AAV.
Methods: Eligible subjects were randomized 1:1 to receive either prednisone or avacopan in combination with either a) cyclophosphamide (oral or IV) followed by azathioprine or b) rituximab (four IV infusions). Randomization was stratified by the treatment regimen (rituximab, IV cyclophosphamide, or oral cyclophosphamide), ANCA serotype, and newly-diagnosed or relapsing disease. Treatment period was 52 weeks; primary efficacy endpoints were the proportion of subjects achieving disease remission at Week 26, and sustained disease remission at Week 52. Remission was defined as a Birmingham Vasculitis Activity Score (BVAS) of zero and not taking glucocorticoids for AAV within 4 weeks prior to Week 26. Sustained remission was defined as being in remission at Week 26 and also subsequently in remission as defined above at Week 52. Any relapse of AAV between Weeks 26 and 52 was considered not achieving sustained remission. Results: 330 subjects were randomized and dosed: 166 in avacopan and 164 in prednisone arms. At Week $26,72.3 \%$ subjects achieved remission in the avacopan arm compared to $70.1 \%$ in the prednisone arm ( $p<0.0001$ for non-inferiority) At Week 52, 65.7\% subjects achieved sustained remission in the avacopan arm compared to $54.9 \%$ in the prednisone arm achieving both non-inferiority and superiority to prednisone $\operatorname{arm}(\mathrm{p}=0.0066$ for superiority of avacopan).

The avacopan arm had a significant reduction in glucocorticoid-related toxicity compared to the prednisone arm as measured by the Glucocorticoid Toxicity Index (GTI) of Cumulative Worsening Score $(\mathrm{p}=0.0002)$ and Aggregate Improvement Score $(p=0.0082)$.

In subjects with renal disease at baseline, the avacopan arm showed a mean increase in estimated glomerular filtration rate (eGFR) of $7.3 \mathrm{~mL} / \mathrm{min} / 1.73 \mathrm{~m} 2$ from baseline to week 52 as compared to $4.0 \mathrm{~mL} / \mathrm{min} / 1.73 \mathrm{~m} 2$ increase in the prednisone arm $(\mathrm{p}=0.0259)$.

Overall subject incidence of serious adverse events (SAEs) was generally consistent with previous AAV trials at $45.1 \%$ and $42.2 \%$ for prednisone and avacopan groups, respectively. Serious infections were $15.2 \%$ and $13.3 \%$, serious hepatic adverse events $3.7 \%$ vs $5.4 \%$, and SAEs of white blood cell count decreases were $4.9 \%$ vs $2.4 \%$ for prednisone and avacopan, respectively. No meningococcal infections were reported.

Conclusion: Avacopan treatment resulted in remission in AAV patients receiving rituximab or cyclophosphamide/azathioprine at a rate that was non-inferior to the active comparator prednisone at week 26 and superior to prednisone in sustained remission at Week 52 . A significant reduction in glucocorticoid-related toxicity was observed in the avacopan vs. prednisone arms. Significant increase in eGFR in subjects with renal disease was also observed in avacopan vs. prednisone. The safety profile of avacopan appears acceptable for development in AAV. Avacopan treatment for AAV is efficacious and exhibits benefits not seen with chronic prednisone therapy.

References: None.

Disclosure of Interests: Peter A Merkel Grant/research support from: AstraZeneca, Boeringher-Ingelheim, Bristol-Myers Squibb, Celgene, ChemoCentryx, Forbius, Genentech/Roche, Genzyme/Sanofi, GlaxoSmithKline, InflaRx Kypha, TerumoBCT, Consultant of: Abbvie, AstraZeneca, Biogen, Boeringher-Ingelheim, Bristol-Myers Squibb, Celgene, ChemoCentryx, CSL Behring, For bius, Genentech/Roche, Genzyme/Sanofi, GlaxoSmithKline, InflaRx, Insmed, Jannsen, Kiniksa, Pfizer, Sparrow, Talaris, David Jayne Grant/research support from: ChemoCentryx, GSK, Roche/Genentech, Sanofi-Genzyme, Consultant of: Astra-Zeneca, ChemoCentryx, GSK, InflaRx, Takeda, Insmed, Chugai Boehringer-Ingelheim, Huibin Yue Shareholder of: ChemoCentryx, Employee of: ChemoCentryx, Thomas Schall Shareholder of: ChemoCentryx, Employee of: ChemoCentryx, Catherine Kelleher Shareholder of: Amgen, ChemoCentryx, Inc., Grant/research support from: Not active, Consultant of: Independent Consultant in the past, Employee of: ChemoCentryx, Inc., Pirow Bekker Shareholde of: Stock options ChemoCentryx, Consultant of: ChemoCentryx, Employee of: ChemoCentryx

DOI: 10.1136/annrheumdis-2020-eular.1073

\section{\begin{tabular}{|l|l|l|l|}
\hline OP0012 & TNF INHIBITORS ARE ASSOCIATED WITH A REDUCED
\end{tabular} RISK OF VENOUS THROMBOEMBOLISM COMPARED TO CSDMARDS IN RA PATIENTS}

M. Schaefer ${ }^{1}$, M. Schneider ${ }^{2}$, A. Graessler ${ }^{3}$, W. Ochs ${ }^{4}$, A. Zink ${ }^{1}$, A. Strangfeld ${ }^{1}$ ${ }^{1}$ German Rheumatism Research Centre, Berlin, Germany; ${ }^{2}$ Scientific Advisory Board, Duesseldorf, Germany; ${ }^{3}$ Rheumatologist, Pirna, Germany; ${ }^{4}$ Rheumatologist, Bayreuth, Germany

Background: While the short-term use of bDMARDs up to 180 days has been associated with an increased risk of venous thromboembolism (VTE) compared to csDMARDs in patients with rheumatoid arthritis (RA), the long term use of more than 730 days has been associated with a decreased risk based on claims data [1]. Among patients with inflammatory bowel disease, observational data indicated that TNF inhibitors may have a protective effect regarding the VTE risk [2]. 